\title{
ANÁLISE DE SOBREVIDA DE MENINGITE PIOGÊNICA EM CRIANÇAS
}

\author{
RITA LUCENA, IRENIO GOMES, JULIETA GÓES, AILTON MELO
}

\begin{abstract}
RESUMO - Com o objetivo de estabelecer a letalidade intra-hospitalar de meningite piogênica em crianças da cidade de Salvador, realizamos análise de todos os prontuários dos pacientes com idade inferior a 15 anos admitidos no Hospital Couto Maia, entre 1990 e 1992, segundo publicado anteriormente. As curvas de sobrevida baseadas nas taxas de letalidade e no tempo de permanência hospitalar foram analisadas, comparando-se os grupos de etiologia identificada e não identificada. A mesma análise foi utilizada para comparar os três agentes etiológicos mais prevalentes na faixa etária pediátrica ( $H$. influenzae, $N$. meningitidis e $S$. pneumoniae). Não houve diferença estatística entre as curvas de sobrevida do grupo identificado e não identificado. Comparando-se os três agentes, observamos que $S$. pneumoniae foi responsável pela maior letalidade intra-hospitalar e $N$. meningitidis apresentou a melhor evolução. Concluímos que esforços devem ser feitos para estabelecer variáveis preditoras de letalidade de meningites piogênicas que possam ser identificadas no momento da admissão hospitalar.
\end{abstract}

PALAVRAS-CHAVE: meningite piogênica, crianças, sobrevida, letalidade, permanência hospitalar.

\section{Survival analysis of acute pyogenic meningitis in children}

ABSTRACT - In order to determine the survival curves of lethality in acute bacteral meningitis (ABM) in children, we reviewed the charts of all patients admitted to the Hospital Couto Maia from January 1990 to December 1992. The Kaplan-Meir analysis was used to compare the survival rate and hospitalar permanence of patients with identified pathogens with those whose bacteria were not determined. The same analysis was used to compare the curves of the three most frequent agents. Statistical difference between the identified and nonidentified groups was not observed. The analysis of the three curves shows that the first 24 hours were responsible for the most elevated lethality rate. When the curves are compared, it is clear that S. pneumoniae has the most important intrahospitalar lethality and $N$. meningitidis the most benign evolution. We conclude that efforts have to be made to determine which variables are related to prognosis of ABM at the first day of hospital admission.

KEY WORDS: acute pyogenic meningitis, children, survival analysis, lethality.

$\mathrm{Na}$ Bahia, a taxa de letalidade por meningite aguda piogênica é considerada alta em relação àquelas observadas em países desenvolvidos ${ }^{1-3}$. Anteriormente, descrevemos fatores de risco para letalidade intra-hospitalar ${ }^{3}$ e o curso clínico de meningites agudas em pacientes internados no Hospital Couto Maia $(\mathrm{HCM})^{1}$. No entanto, restavam muitas dúvidas sobre a evolução dos pacientes ao longo do período de internação. No HCM, a letalidade por meningite piogênica em crianças, no período de 1990 a 1992 , foi $20,9 \%^{1}$. Entretanto, esta taxa não expressa o período de maior risco para óbito no curso do internamento.

Com o objetivo de estudar a letalidade e o tempo de permanência hospitalar de acordo com a etiologia, utilizamos o método de Kaplan-Meier para estabelecer a sobrevida de pacientes com meningite piogênica no Estado da Bahia, analisando uma coorte retrospectiva de casos internados no HCM entre janeiro-1990 e dezembro-1992.

Serviço de Neurologia- Universidade Federal da Bahia. Aceite: 30-outubro-1997.

Dr. Ailton Melo - Avenida Magalhães Neto 735/802 - 41820-141 Salvador BA - Brasil. 


\section{MÉTODOS}

Informações do prontuário de pacientes com idade inferior a 15 anos, admitidos no HCM entre janeiro1990 e dezembro-1992, com diagnóstico de meningite piogênica, foram estudados a partir do preenchimento de questionários específicos.

Dados referentes a tempo de internação, evolução, data de admissão e desfecho foram inseridos em uma base de dados e analisados para construção de curvas de sobrevida (SPSS for Windows). Para análise estatística utilizamos o $\chi^{2}$, teste de Kruskall-Wallis e log rank.

Os critérios utilizados para definição de meningite piogênica foram: cultura positiva no líquor para bacterias piogênicas, presença de diplococo Gram negativo no líquor; hemocultura positiva para $N$. meningitidis e celularidade liquórica superior a 1000 células com predomínio de polimorfonucleares ou visualização de bactérias pelo método de Gram no líquor. A partir de um dos três primeiros critérios era possível estabelecer a etiologia ${ }^{3}$.

Curvas de sobrevida baseadas nas taxas de letalidade e no tempo de permanência hospitalar foram construídas considerando-se a etiologia ter sido ou não definida. Em seguida, comparamos as curvas relativas aos três principais agentes etiológicos ( $H$. influenzae, N. meningitidis e S. pneumoniae).

Para a elaboração das curvas de sobrevidas, excluimos os casos de meningites recidivantes, pacientes submetidos a procedimentos neurocirúrgicos prévios ou vítimas de traumatismo cranioencefálico aberto. Durante o acompanhamento, foram excluídos também pacientes transferidos para outros hospitais, aqueles que tiveram alta a pedido antes da resolução do quadro e os pacientes que morreram após 40 dias do internamento,quando a meningite não foi considerada a causa do óbito.

Finalmente, foram construídas curvas de sobrevida incluindo todos os pacientes e atribuindo um mesmo desfecho (alta ou óbito) para todos os que foram tranferidos e excluídos das análises anteriores.

\section{RESULTADOS}

Entre 1990 e 1992 foram admitidos, no HCM, 1700 casos de meningite, sendo 1190 em crianças com idade inferior a 15 anos. Considerando esta faixa etária, 528 pacientes preencheram pelo menos um dos critérios definidos para meningite piogênica. No entanto, para a análise de sobrevida foram excluídos 29 indivíduos, dos quais 20 foram transferidos, 7 tiveram alta a pedido dos familiares antes do sétimo dia de internação e 2 faleceram após 40 dias de admissão hospitalar.

Dos pacientes que permaneceram no estudo $(n=499), 395(79,2 \%)$ tiveram alta hospitalar após resolução do processo infeccioso e 104 (20,8\%) evoluíram para o óbito. Em 73,3\% dos casos $(\mathrm{n}=366)$, o agente etiologico foi identificado, sendo por ordem decrescente de frequência $H$. influenzae (41,5\%), N. meningitidis $(36,6 \%), S$. pneumoniae $(16,4 \%)$ e outros $(5,5 \%)$.

Em média, os pacientes com meningite de etiologia definida permaneceram internados 15,25 $( \pm 8,49)$ dias, enquanto o tempo médio de internação para os de etiologia não definida foi 14,87 $( \pm 8,71)$ dias (Kruskall-Wallis:3,33 p=0,07). Comparando as curvas de sobrevida de permanência hospitalar para os dois grupos, observamos que elas não diferiram $(\mathrm{p}=0,34)$. No entanto, foram diferentes quando comparamos em relação ao agente etiológico $(\mathrm{p}<0,001)$ (Fig 1). Embora não tenha havido diferença do tempo de permanência hospitalar entre $H$. influenzae e $S$. pneumoniae, as curvas apresentadas por estes agentes foram nitidamente diferentes daquela observada nos casos de N. meningitidis. Verificamos que $75 \%$ dos pacientes com meningite meningocócica deixaram o hospital num período inferior a 12 dias, o mesmo ocorrendo em aproximadamente $40 \%$ dos pacientes com S. pneumoniae e $H$. influenzae (Fig 2). A média de tempo de internação foi 17,2 dias para H.influenzae, 12,5 dias para $N$. meningitidis e 15,3 dias para $S$. pneumoniae, sendo a diferença estatisticamente significante (Kruskall-Wallis: 52,14 p<0,0001).

Embora a taxa de letalidade não tenha diferido no grupo de etiologia identificado e não identificado, respectivamente 21 e $20,3 \%\left(\chi^{2}: 0,03 \quad \mathrm{p}=0,86\right)$, observamos que o tempo médio de ocorrência do óbito foi diferente (Fig 3). Nos pacientes com etiologia definida, este foi 2,51 $( \pm 4,76)$ dias e, nos de etiologia não definida, $6,41( \pm 8,29)$ dias (Kruskall-Wallis: 3,94 p=0,047). Ao compararmos as curvas de sobrevida baseadas nas taxas de letalidade para os dois grupos, verificamos que elas não diferiram ( $\mathrm{p}=0,78)$ (Fig 4).

Considerando os três principais agentes etiológicos, constatamos taxa de letalidade de $18,4 \%$ para $H$. influenzae, $14,5 \%$ para $N$. meningitis e $41,7 \%$ para $S$. pneumoniae, sendo a diferença observada 


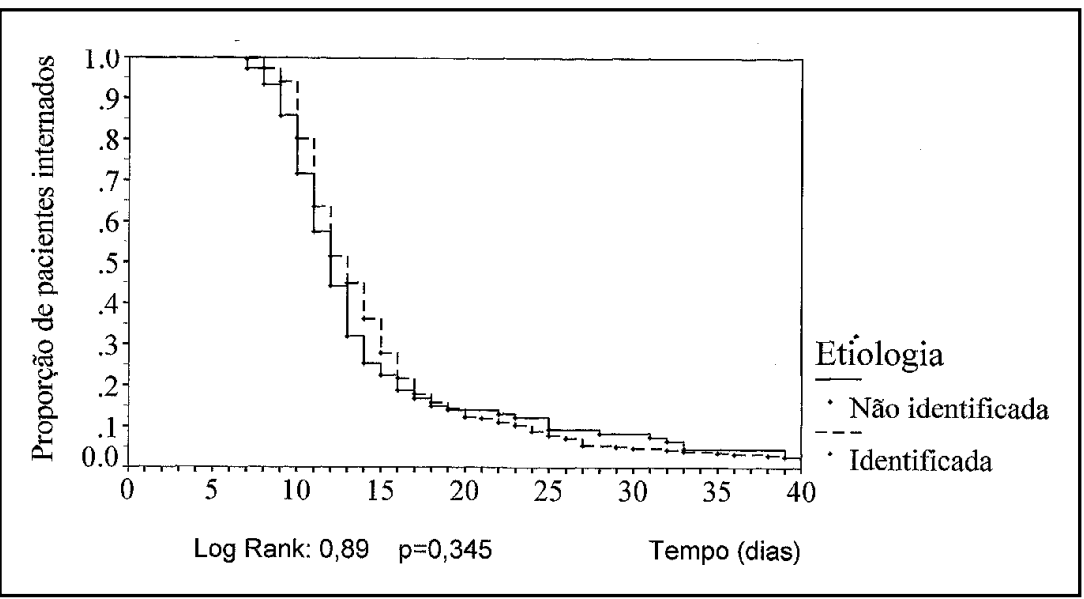

Fig 1. Permanência hospitalar em crianças ( $<15$ anos) com meningite piogênica de acordo com a identificação da etiologia.

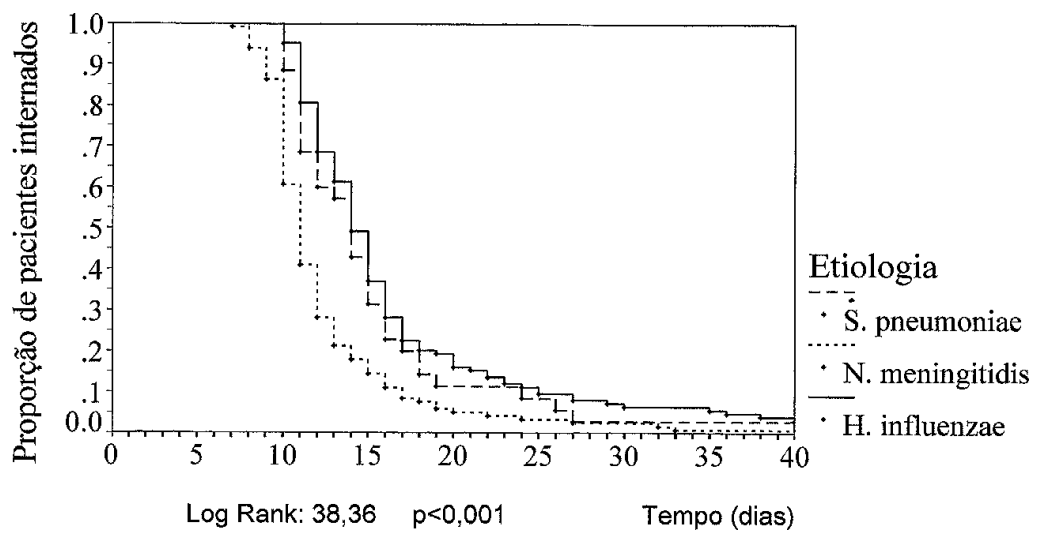

Fig 2. Permanência hospitalar em crianças (<15 anos) com meningite piogênica de acordo com o agente etiológico.

significante $\left(\chi^{2}: 22,12 \mathrm{p}<0,0001\right)$. No entanto, ao compararmos o tempo médio para a ocorrência do óbito, não observamos diferença entre os três patógenos estudados (Kruskall-Wallis: 0,74 p=0,69), sendo este $1,18( \pm 1,44)$ dias para $H$. influenzae, $1,71( \pm 2,23)$ dias para $N$. meningitidis e $2,48( \pm 4,01)$ para o $S$. pneumoniae.

Observamos que não houve diferença estatisticamente significante quando incluimos, para elaboração de curvas de sobrevida baseada na taxa de letalidade, os pacientes tranferidos, aos quais foi atribuído um mesmo desfecho, alta ou óbito (log rank: 1,8 $\mathrm{p}=0,18)$

\section{DISCUSSÃO}

Maior ocorrência de óbito nas primeiras 48 horas de admissão hospitalar e taxa de letalidade maior nos casos de meningite causada por $S$. pneumoniae têm sido descritas por outros autores ${ }^{2,4}$.

Embora conhecendo a taxa de letalidade e de complicações neurológicas por meningite piogênica em crianças na Bahia, apenas a partir da elaboração de curvas de sobrevida, tornou-se 


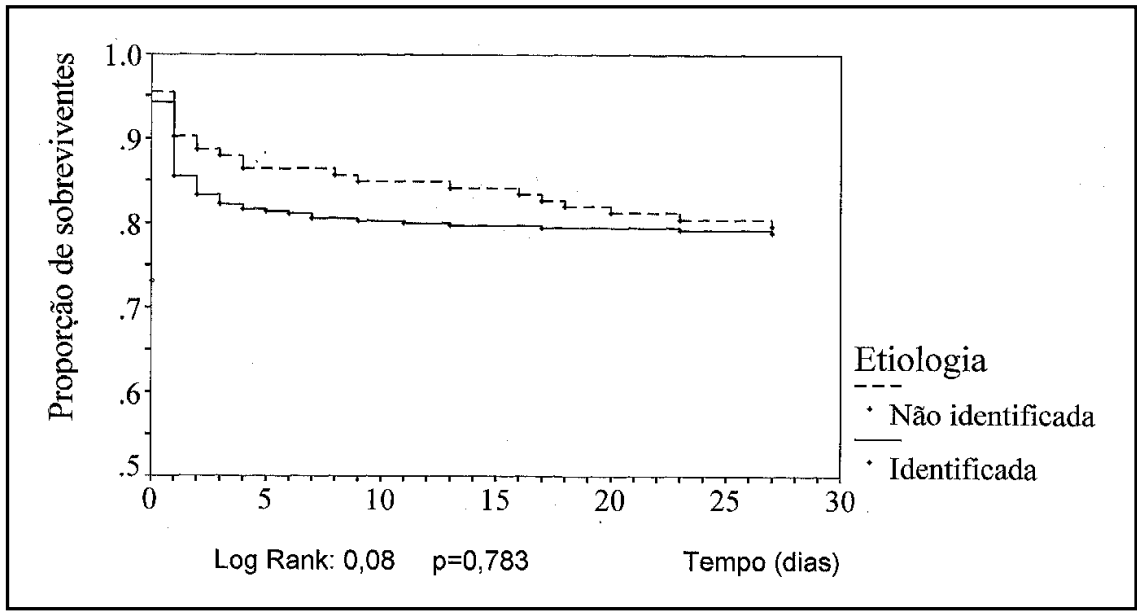

Fig 3. Letalidade intra-hospitalar em crianças (<15 anos) com meningite piogênica de acordo com a identificação da etiologia.

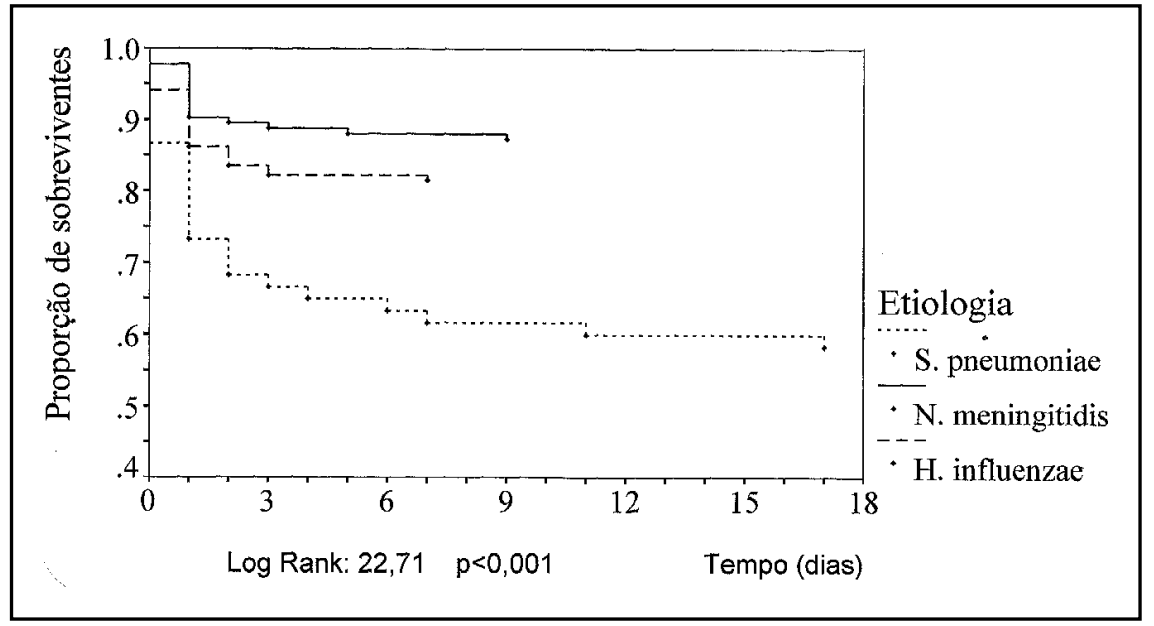

Fig 4. Letalidade intra-hospitalar em crianças (<15 anos) com meningite piogênica de acordo com o agente etiológico.

possível verificar a probabilidade de alta hospitalar e de óbito a cada dia de internação para cada um dos agentes etiológicos mais incidentes em crianças.

Mesmo não sendo possível descrever o desfecho dos pacientes excluídos das análises de sobrevida iniciais, este dado não comprometeu a validade dos resultados, já que, ao construirmos curvas considerando todas as crianças transferidas como óbito ou alta, não foi observada diferença.

Por outro lado, a transferência de pacientes do HCM se dá usualmente não pela gravidade do quadro, mas pela disponibilidade de recursos da família da criança, o que permite acesso a outras instituições de saúde. Os pacientes transferidos para outros hospitais para submeterem-se a procedimento neurocirúrgico retornam ao HCM logo após sua realização, não havendo nesses casos de suposta maior gravidade, perda de acompanhamento.

Observamos média de permanência hospitalar maior do que a duração de tratamento preconizada ${ }^{5}$. Até o momento, não foi possível identificar as variáveis que determinam o tempo de internação maior que o esperado. Provavelmente, contribuem fatores relacionados às diferenças de 
condutas terapêuticas, à dificuldade de investigar as possíveis complicações, à falta de uniformidade dos critérios de cura ${ }^{6}$. Em estudo prévio, observamos alta taxa de complicações neurológicas agudas em crianças com meningite piogênica ${ }^{3}$, índice próximo aos observados em países subdesenvolvidos dos continentes asiático e africano ${ }^{7-12}$ que pode se constituir em fator adicional determinante do maior tempo de internação.

Recentemente, na Dinamarca, foi verificada relação diretamente proporcional entre celularidade liquórica à admissão hospitalar e tempo de internação necessário para resolução do processo infeccioso ${ }^{13}$. Em estudo prévio, realizado no HCM, verificamos que $81,6 \%$ das crianças admitidas com diagnóstico de meningite piogênica tiveram celularidade superior a $1000 \mathrm{cels} / \mathrm{mm}^{3}$. É possível que a maior permanência hospitalar verificada nos dois estudos esteja relacionada ao critério clínico de utilizar baixa celularidade como indicador de cura para pacientes com meningite piogênica.

Em estudo realizado na Bahia ${ }^{2}$, verificou-se que, no decênio entre 1973 e 1982, 50\% dos óbitos ocorreram nas primeiras 48 horas de internação, o que poderia refletir, segundo os autores, a natureza fulminante da enfermidade, as precárias condições de saúde da população estudada ou ainda admissão hospitalar tardia.

Todos os dados aqui apresentados apontam para o melhor prognóstico da meningite meningocócica quando comparado ao observado em meningites causadas pelos outros agentes etiológicos. Em estudo prévio, verificamos que, enquanto complicações neurológicas agudas ocorreram em 78,8\% dos pacientes com meningite pneumocócica, estas foram observadas em 40,3\% dos pacientes com meningite meningocócica, restringindo-se apenas à ocorrência de crises epilépticas e de diminuição do nível de consciência ${ }^{1}$. Este é um fator que, sem dúvida, interfere no tempo de internação.

Outro aspecto de relevância observado neste estudo foi a ocorrência do óbito mais tardiamente nas crianças com meningite de etiologia indefinida quando comparadas àquelas em que o agente foi identificado, embora a taxa de letalidade global tenha sido semelhante nos dois grupos.

Embora a análise de Kaplan Meir forneça informações importantes sobre a probabilidade de ocorrência de um evento específico a cada instante do período de acompanhamento ${ }^{14}$, estudos para determinação de variáveis preditoras de tempo de permenência hospitalar são necessários. É provável que, a partir do conhecimento destes determinantes, seja possível lançar mão de estratégias visando a controlá-los e, consequentemente, encurtar o período de internação.

\section{REFERÊNCIAS}

1. Lucena R, Gomes I, Ferreira A, et al. Características clínicas e laboratoriais de meningites bacterianas em crianças. Arq Neuropsiquiatr 1996;54:571-576.

2. Bryan JP, Silva HR, Tavares A, Rocha H, Scheld WM. Etiology and mortality of bacterial meningitis in Northeastern Brazil. Rev Inf Dis 1990;12:128-135.

3. Gomes I, Melo A, Lucena R, et al.. Prognosis of bacterial meningitis in children. Arq Neuropsiquiatr 1996;54:407-411.

4. Akpede GO. Presentation and outcome of sporadic acute bacterial meningitis in children in the African meningitis belt: recent experience from northern Nigeria highlighting emergent factors in outcome. West Afr J Med 1995;14:217-226.

5. Decazes JM. Purulent meningitis: epidemiology, etiology, diagnosis, development, prognosis, prevention, treatment. Rev Pract 1995;45:607-616.

6. Anttila M. Clinical criteria for estimating recovery from childhood bacterial meningitis. Acta Pediatr 1994;83:63-67.

7. Bhat BV, Verma IC, Puri RK, Srinivasan S, Nalini P. A profile of pyogenic meningitis in children. J Indian Med Assoc 1991;89:224-227.

8. Cadoz M, Denis F, Diop Mar I. Etude épidémiologique des cas de méningites purulentes hospitalisés à Dakar pendant la décennie 1970-1979. Bulll Org Mond Santé 1981;59:575-584.

9. Ford H, Wright J. Bacterial meningitis in Swaziland: an 18 month prospective study of its impact. J Epidemiol Comm Health 1994;48:276-280.

10. Ozumba UC. Acute bacterial meningitis in Enugu, Nigeria. 1 April 1989 to 31 March 1993. Cent Afr J Med 1995;41:93-99.

11. Salaun-Saraux P, Saraux A, Lepage P, et al.. Septic meningitis in children in Rwanda from 1983 to 1990: retrospective study at the Kigali Hospital Center. Med Trop Mars 1995;55:41-45.

12. Wright JP, Ford HL. Bacterial meningitis in developing countries. Trop Doc 1995;25:5-8.

13. Andersen J, Backer V, Jensen E, Voldsgaard P, Wandall JH. Acute meningitis of unknown aetiology: analysis of 219 cases admitted to hospital between 1977 and 1990. J Infect 1995;31:115-122.

14. Fletcher RH, Fletcher SW, Wagner EH. Clinical epidemiology: the essentials. 3.Ed. 1996:111-135. 